\title{
Digital Disruption
}

\author{
Daniel A. Skog $\cdot$ Henrik Wimelius $\cdot$ Johan Sandberg
}

Received: 31 January 2018/Accepted: 8 June 2018/Published online: 16 July 2018

(C) The Author(s) 2018

Keywords Digital disruption · Digital innovation ·

Disruptive innovation theory

\section{Beyond the Buzz}

Prominent digital innovations such as Uber, Airbnb, and Spotify challenge the existence of dominant firms and cause severe systemic effects in industries and markets. Such radical digital innovation and its wider systemic effects - frequently referred to as digital disruption - are attracting substantial attention amongst both researchers and practitioners.

The concept of digital disruption is often framed as a type of environmental turbulence induced by digital innovation that leads to the erosion of boundaries and approaches that previously served as foundations for organizing the production and capture of value (Karimi and Walter 2015; Weill and Woerner 2015; Rauch et al. 2016). This view of digital disruption as a major cause of fundamental creative destruction processes is echoed in white papers of IT and management firms (e.g., Bonnet et al. 2015; Garcia et al. 2015; Knickrehm et al. 2016). Such publications frequently emphasize the rapid and systemic impacts of

Accepted after one revision by Prof. Dr. Weinhardt.

D. A. Skog $(\bowtie) \cdot$ Dr. H. Wimelius · Dr. J. Sandberg

Department of Informatics, Umeå University, Campustorget 5,

90187 Umeå, Sweden

e-mail: daniel.a.skog@umu.se

Dr. H. Wimelius

e-mail: henrik.wimelius@umu.se

Dr. J. Sandberg

e-mail: johan.sandberg@umu.se digital disruption. For example, it is argued that digital disruption may shake "the core of every industry" (Bonnet et al. 2015), and induce "short fuse, big bang" situations capable of threatening entire sectors (Farrall et al. 2012).

Given the major potential risks and rewards, several authors have suggested that abilities to either instigate digital disruption and induce systemic change or exploit accompanying changes in core conditions are crucial for successful firms in the age of digitalization (Lucas $\mathrm{Jr}$ et al. 2013; Legner et al. 2017). However, while practitioners and scholars agree on the general framing of digital disruption, its precise meaning and relation to other prevalent concepts in the digital innovation discourse remain unclear. Moreover, there is at most limited understanding of how digital innovation triggers the dynamic processes that may generate digital disruption. Furthermore, digital disruption is often conflated with disruptive innovation theory (Christensen 1997, 2006; Christensen et al. 2015).

In this paper, we propose a consolidated definition of digital disruption grounded in recent research in Information Systems (IS) and provide a conceptualization of how digital disruption may arise through embedding digital innovations that carry deviant value logics in digital ecosystems. Our aims are to stimulate further theorization of this process and support future research on the relationship between digital innovation and industry upheavals.

\section{Defining Digital Disruption}

The term disruption has several connotations, which have clouded understanding and development of disruptive innovation theory for more than 20 years. In disruptive innovation theory, disruption refers to a very specific process that explains how entrants can successfully compete 
with incumbents (Christensen et al. 2015). It is concerned with business-model innovation that enables entrants to enter markets with cheap, easy to use, but low-performing products (Christensen 2006; Christensen et al. 2015). The competitive relationship between incumbents and entrants, and the specific means through which the latter enter the market, are key boundary conditions for Christensen's conceptualization that are rarely exhibited by cited empirical examples of digital disruption (Christensen et al. 2015; Chase 2016). Perhaps more importantly, technological innovation plays a limited role in disruptive innovation theory and it is mainly concerned with competitive dyads, as opposed to systemic impacts on industries.

In common parlance, however, the verb disrupt has slightly different meanings: to prevent something, especially a system, process, or event, from continuing as usual or as expected (Cambridge online dictionary), to break apart, to throw into disorder, or to interrupt the normal course or unity of, for example, an industry with new technology (Merriam-Webster online dictionary).

Evidently, extant IS research has primarily drawn upon the general notion of disruption, commonly framing digital disruption as a type of digital technology-induced environmental turbulence capable of producing industry-level upheaval. As specific manifestations of digital disruption, digitization and digital platforms have, for example, been highlighted as processes or artefacts that can lead to dissolution of core industry conditions for organizing the production and capture of value (El Sawy et al. 2010; Karimi and Walter 2015; Tan et al. 2015; Berghaus and Back 2016; Rauch et al. 2016). Other authors have attributed the origination of digital disruption to specific actors, digital disruptors, that leverage digital technologies to undermine established industry models of consumption, competition and resourcing (Tan et al. 2015; Wenzel et al. 2015; Elbanna and Newman 2016).

Digital disruption is generally perceived from the perspective of firms that are heavily invested in old conditions and whose typical or planned course of development is interrupted. As the proliferation of certain digital processes or artefacts leads to change in established industry structures, established firms face severe pressure to respond. Such responses can prompt fundamental change to operations (Karimi and Walter 2015), the technologies that support legacy business models (Rauch et al. 2016) and even the identities of the organizations and professionals within them (Utesheva et al. 2015). When firms face the threat of digital disruption there is often an acute need to react due to the rapidity and systemic nature of environmental change along with diminishing business results. However, it is generally difficult to change historically successful firm structures that have emerged from adaptation to previously prevalent environmental conditions (Lucas and Goh 2009; Karimi and
Walter 2015; Wenzel et al. 2015; Westerman and Bonnet 2015; Rauch et al. 2016).

Less attention has been paid to the opportunities that digital disruption may bring for firms that are unburdened by digital debt from legacy investments to exploit new digital options (Sandberg et al. 2014; Rolland et al. 2018). Elbanna and Newman (2016) serves as a notable exception as they note how an initial digital innovation and its systemic effects may serve as a forerunner for subsequent start-ups that imitate or refine it.

Consideration of contemporary empirical processes, the general notion of disruption and extant research leads us to suggest three fundamental characteristics of digital disruption. First, digital disruption processes originate from digital innovations and quickly erode competitive positions. Second, they impact systems of value-creating actors by breaking and recombining linkages among resources, often facilitating more direct interactions and transactions. Third, the originating digital innovation processes are orchestrated by one or multiple firms, but effects on value creation and capture are systemic. Hence, we propose the following definition of digital disruption:

The rapidly unfolding processes through which digital innovation comes to fundamentally alter historically sustainable logics for value creation and capture by unbundling and recombining linkages among resources or generating new ones.

Recognizing the core role of innovation in fundamental restructuring processes, we examine key elements of digital innovation to explore how and why digital disruption may emerge and generate favorable or potentially fatal conditions for different actors.

\section{Constitutive Elements of Digital Disruption}

In the digital innovation discourse, multiple related terms, with various nuances, are sometimes used interchangeably (Legner et al. 2017; Nambisan 2018). Here, we seek to clarify our perspective by describing three key constitutive elements of digital disruption: digital innovation, digital ecosystems and value logics. We locate digital innovation and disruption within a larger process of change, namely digital transformation, i.e. "the combined effects of several digital innovations bringing about novel actors (and actor constellations), structures, practices, values, and beliefs that change, threaten, replace or complement existing rules of the game within organizations, ecosystems, industries or fields" (Hinings et al. 2018, p. 53). Digital transformation is thus an aggregated effect that both triggers and is spurred by numerous digital innovations, some of which may generate systemic "shocks", i.e. digital disruption. Digital 
disruption is distinct from digital transformation in at least two respects. First, digital disruption is the manifestation of specific innovation processes rather than aggregated effects. As such, digital disruption processes have identifiable agents in terms of both initiators and targets, and each digital innovation involved is intended to attack, undermine or render obsolete other actors' mechanisms for value creation and capture. Thus, in a digital disruption process, cause and effects can be traced from firm to systemic level, and back to firm level. Second, digital disruption unfolds more rapidly than digital transformation.

\subsection{Digital Innovation}

Digital innovation has been defined narrowly, focusing on the design process. For example, Yoo et al. (2010, p. 725) refer to it as "the carrying out of new combinations of digital and physical components to produce novel products". However, it has also been defined more broadly in terms embracing the outcome as well as design phases. For example, Nambisan et al. (2017, p. 224) describe it as "the creation of (and consequent change in) market offerings, business processes, or models that result from the use of digital technology". Similarly, Fichman et al. (2014, p. 330) refer to digital innovation as "a product, process or business model that is perceived as new, requires some significant changes on the part of adopters, and is embodied in or enabled by IT".

Regardless of whether digital innovation is seen as a process or outcome, it is generally understood as enabled by and driving digital transformation of society. On a societal level, digital transformation includes large-scale digitization (homogenizing analogue information into binary code) and exponential improvements in basic computing capabilities, which in turn spurs digitalization, i.e. sociotechnical processes in which digitizing techniques are applied and adopted at large scale in social and institutional contexts (Tilson et al. 2010). Digital infrastructures' propensity for universal standardization and data homogenization enables actors to combine physical and digital elements far more extensively than other forms of technological innovation. As a process, digital innovation is therefore inherently combinatorial and societal digital transformation continuously expands the available design space for digital innovators (Lyytinen and Rose 2003). As outcomes, digital innovations therefore materialize as composites of existing and new digital and physical technologies. As both process and outcome, digital innovation is therefore said to be self-referential, i.e. it provides enabling and constraining conditions for further digital innovation (Yoo et al. 2010, 2012).

We conceptualize digital disruption as a phenomenon originating in firm-level processes subsequently affecting industries. Thus, our interest lies in the particular outputs that become exposed to the sociotechnical environment of organizations and the processes through which they are created and embedded in wider contexts. Therefore, digital innovation is understood here as the process of combining digital and physical components to create novel devices, services or business models, bundling them to constitute and enable market offerings, and embedding them in wider sociotechnical environments to enable their diffusion, operation and use. As such, digital innovation is inherently dependent on the technological and business environment to trigger identification of opportunities for novel combinations, provide resources for it, and provide the context for output embedment. Here, we employ the concept of ecosystems to capture this relationship.

\subsection{Digital Ecosystems}

The term digital ecosystem has been assigned various meanings in IS research. For example, Selander et al. (2013, p. 184) emphasize organizational networks by defining it as "a collective of firms that is inter-linked by a common interest in the prosperity of a digital technology for materializing their own product or service innovation". Kallinikos et al. (2013, p. 364) implicitly define it as the wider environment in which "digital objects are embedded in shifting interdependencies with other entities", while Adomavicius et al. (2008) emphasize technological networks by referring to IT ecosystems as collections of information technologies that are related based on a specific use context.

While acknowledging that the term often refers to the sociotechnical systems of actors centered on digital platform technologies (e.g., de Reuver et al. 2017), we build on the definitions above to suggest a more inclusive meaning of the concept. Specifically, rather than being bounded by a particular technology (e.g., a platform), we refer to digital ecosystems as sociotechnical networks of interdependent digital technologies and associated actors that are related based on a specific context of use (Adomavicius et al. 2008). From this perspective, digital ecosystems are characterized by a number of distinct characteristics. First, they emerge as complex and dynamic webs of interdependent sociotechnical elements (including digital technologies, firms, institutions and customers) as the combinatorial and self-referential nature of digital innovation is operationalized (Kallinikos et al. 2013). Second, digital ecosystems often span industry boundaries to comprise heterogeneous actors and technologies from several industries. Third, they often overlap as larger ecosystems that support general purposes (e.g., distribution and use of mobile applications) in turn comprise smaller and more specialized ecosystems (e.g., music streaming). Finally, digital ecosystems are inherently hierarchical where the power to influence others increases with centrality, i.e., actors' influence is generally 
related to the number of external actors that depend on them (Adomavicius et al. 2008).

\subsection{Value Logics}

Over time, the term logics has become increasingly associated with digital innovation. For example, Yoo et al. (2010) suggest that digital product architectures breed a new dominant logic for organizing innovation. Further, Nambisan et al. (2017) argue for new theorizing logics that do not rely on assumptions inherited from innovation management theories to improve understanding of digital innovation phenomena. Referring specifically to institutional logics, Hinings et al. (2018) note that digital innovations that become central in ecosystems may also become standard-setting and hence able to impose norms and values on others by coordinating, enabling and constraining their actions. This resonates with descriptions of platform logics where the idea of deriving value from platform ecosystems is reflected in the architecture and governance structures designed to promote or hinder certain behaviors (Van Alstyne et al. 2016). Over time, embedment of such logics in industries may result in industry-wide shifts in dominant practices, the nature of firm relationships, and conceptions of value and leadership (Garud et al. 2002; Gawer and Phillips 2013).

Building on these theorizations, we conceptualize digital innovation as carrying specific kinds of value logics, i.e. foundational rationales for designing, bundling and embedding a digital innovation to fruitfully create and capture value. Value logics provide a rationale that guide actors in forming a business-model and in developing the device or service that enables it. In other words, value logics materialize in digital market offerings, and they become exposed to other actors when digital innovations are introduced into digital ecosystems. Once a digital innovation is adopted and used in a digital ecosystem, it may coordinate, enable and constrain the actions of others for the purpose of fulfilling its value logic.

These three constitutive elements of digital disruption processes are summarized in Table 1.

\section{A Research Agenda on Digital Disruption Dynamics}

To stimulate and support further work on digital disruption, we propose a conceptual model (Fig. 1) that illustrates how the core constitutive elements detailed above may actualize digital disruption. The model is processual and structured according to stages of digital innovation (discovery, development, diffusion and impact) as described by Fichman et al. (2014). Arrows represent transitions between stages, but also critical junctures where we suggest the process may be aborted or lose its disruptive character if necessary conditions are not met.

In the discovery stage, the potential for materializing ideas into digital innovations is explored. Actors engage in an iterative process of invention, selection and testing as they examine combinations of both internal resources and external technologies (Fichman et al. 2014). Hence, actors explore opportunities raised, and limitations imposed, by digital transformation and the ecosystem of interest. The design space available, the capacities to identify and exploit opportunities, and the radicalness of the idea jointly influence the likelihood for emergence of a digital innovation capable of digital disruption. In order for the intended artefact to proceed from idea to useable output, we suggest it must meet at least two essential criteria; it must incorporate a value logic that deviates substantially from the dominant logic in the focal ecosystem, and it must be deemed technologically and financially feasible.

Our conception of digital disruption initiation indicates that further investigation is required into how radical ideas are generated in the context of digital innovation, how their potential for producing digital disruption can be evaluated at early stages, and how a deviating value logic can be materialized in a market offering. Specific opportunities for further research may involve:

- How do ideas that carry the potential for digital disruption emerge? Potentially disruptive ideas are likely to stem from a deep understanding of industries and markets as well as the actors and technologies that support them. Indicative research topics on this issue includes if, and in that case how, firms can design innovation projects to increase the potential for digital disruption.

- How can the combinatorial nature of digital innovation be leveraged to produce synergies between external selection and internal invention? The ostensible ease with which digital elements can be combined in theory may often prove to be challenging in practice. Particularly for incumbent firms that are products of existing dominant logics, acts of selection and invention may seem irrational when they conflict with this dominant logic and internal organizational and cognitive structures.

In the subsequent development stage, the idea is developed into a useable output (Fichman et al. 2014). This involves introducing the innovation into a focal digital ecosystem where it can draw upon the content, services, networks or devices needed for its operation and use (Adomavicius et al. 2008; Yoo et al. 2010). Here the innovation needs to be deemed compatible with technological standards and governance structures so that it can 
Table 1 Constitutive elements of digital disruption

\begin{tabular}{lll}
\hline Construct & Definition & Foundational literature \\
\hline $\begin{array}{l}\text { Digital } \\
\text { innovation }\end{array}$ & $\begin{array}{l}\text { The process of combining digital and physical components to create novel devices, services or } \\
\text { business models, bundling them to constitute and enable market offerings, and embedding them } \\
\text { in wider sociotechnical environments to enable their diffusion, operation and use }\end{array}$ & $\begin{array}{l}\text { Yoo (2010), Fichman et al. } \\
\text { (2014), Nambisan et al. (2017) }\end{array}$ \\
$\begin{array}{ll}\text { Digital } \\
\text { ecosystem }\end{array}$ & $\begin{array}{l}\text { A sociotechnical network of interdependent digital technologies and associated actors that are } \\
\text { related based on a specific context of use }\end{array}$ & $\begin{array}{l}\text { Kallinikos et al. (2013), } \\
\text { Adomavicius et al. (2008) }\end{array}$ \\
& $\begin{array}{l}\text { Foundational rationales for designing, bundling and embedding a digital innovation to } \\
\text { fruitfully create and capture value. }\end{array}$ & $\begin{array}{l}\text { Hinings et al. (2018), Yoo et al. } \\
\text { (2010), Gawer and Phillips } \\
\text { (2013) }\end{array}$ \\
\hline
\end{tabular}

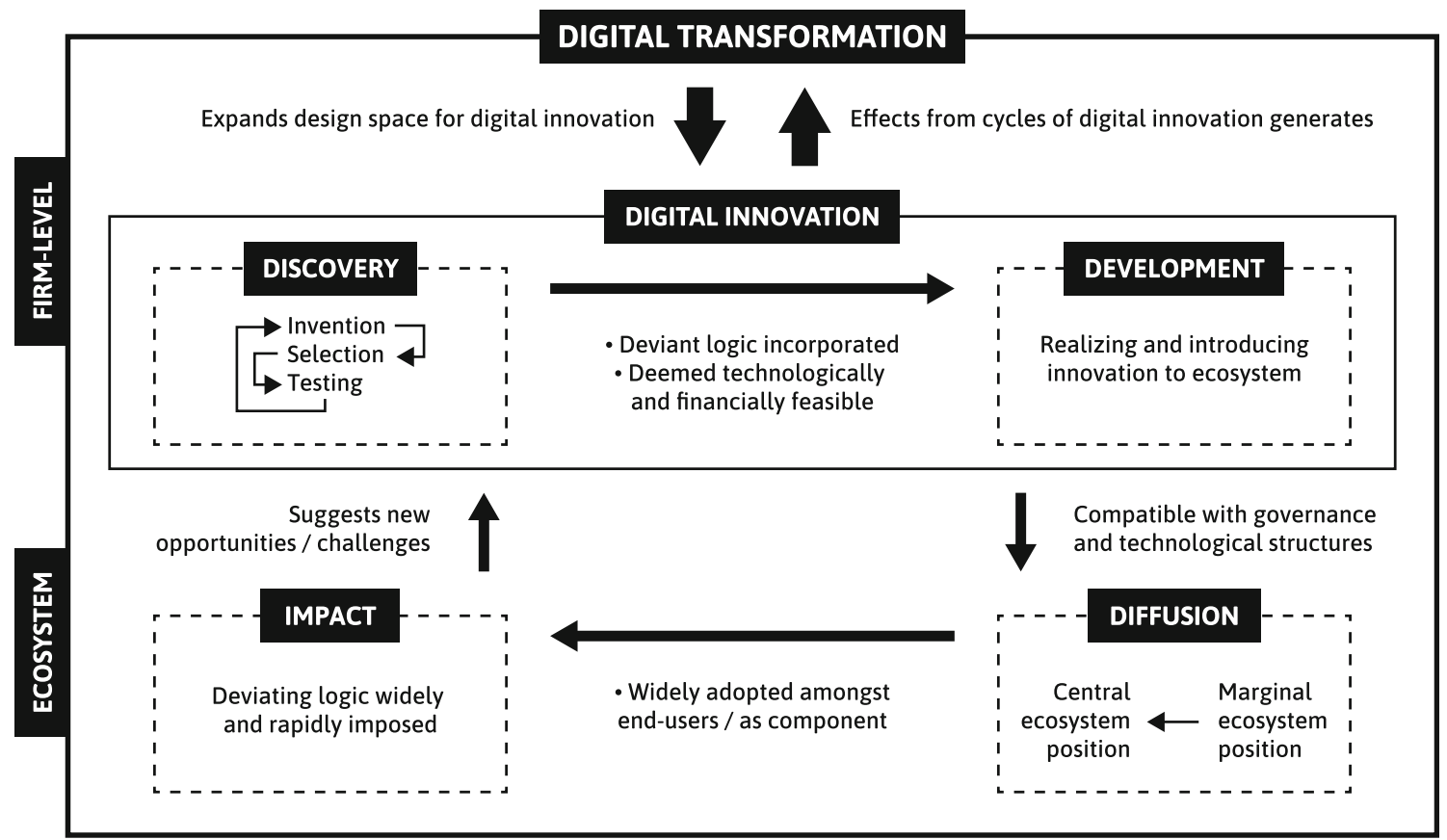

Fig. 1 Conceptual model of digital disruption dynamics

become exposed to end-users and available for adoption as a component in secondary digital innovation processes.

The development stage is essential for producing digital innovation outputs and presenting them to a wider sociotechnical context and raises interesting questions to pursue, including:

- How can digital innovation be managed and packaged to avoid that the materialization of deviant logics is halted by structures upholding a dominant logic? The deviant value logic promoted by an innovation that may induce digital disruption is likely to face resistance when introduced into existing industries and markets. This may call for proactive measures to avoid, outmaneuver or counteract obstacles hindering or constraining digital innovation in the development stage.
- How can governance structures be designed to protect against deviant logics gaining a foothold? Stopping digital disruption before it causes any harm can be crucial for actors that rely on a dominant logic and may be possible through careful governance design. However, doing so is probably only achievable for highly central ecosystem actors who can impose governance structures.

In the diffusion stage, a digital innovation is adopted and used by an increasing population of actors (Fichman et al. 2014). During this stage, both individual elements and their bundling into market offerings are important. A combination of appropriate business model design, aesthetic elements with mass appeal, and service design delivering attractive value propositions can powerfully drive rapid and massive adoption. Increasingly adopted by parties that 
become dependent on it, the digital innovation can start imposing its deviating logic on a wider scale by providing structures that restrict or encourage certain behaviors. We assume this stage to be critical in digital disruption since centrality breeds influence, and adoption breeds centrality. Therefore, wide diffusion amongst end-users and establishment as a central component for many other technologies in the ecosystem are key steps in the initiation of a shift in dominant industry logic. Interesting questions at this stage include:

- How can digital innovations be bundled to stimulate, support and finance rapid adoption? Digital business models often rely on subsidization of one user group to attract other user groups by leveraging positive network effects. This presents the innovating organization with severe challenges, including needs to build and maintain an infrastructure that can support a rapidly growing user base and identify ways to extract financial resources from other sources.

- What environmental conditions enable a digital innovation carrying deviant logics to attain centrality? We presume that environmental conditions will be decisive for diffusion. Specifically, an interesting issue is if and how different contexts may provide conditions that either enable or constrain digital disruption.

Finally, the impact stage focus on the intended and unintended consequences that digital innovations have once diffused (Fichman et al. 2014). In line with our definition of digital disruption, we propose that a digital innovation can alter historically sustainable core conditions for business and operations within industries once it is successfully diffused and able to impose a deviating logic on a wide scale. We suggest that when it has attained a central ecosystem position, a digital innovation can alter core industry conditions that are vital to other actors in at least two ways. It may alter conditions immediately and directly through relationships with adopters that depend on it. This can be achieved through changing technological or governance structures to signal change in accepted and promoted behaviors (Skog 2016). Alternatively (or simultaneously), more gradual change may be induced if diffusion amongst end-users leads to shifts in their behaviors and expectations regarding certain types of digital market offerings. Hence, the impact stage offers several interesting questions, including:

- How may digital ecosystems be leveraged to cause digital disruption in industries not characterized by the presence of a digital ecosystem? Industries and digital ecosystems seldom share boundaries and the latter often spans a collection of actors and technologies from different industries. Through the introduction and diffusion of a digital innovation, it may therefore be possible to extend the purpose of a digital ecosystem to incorporate the particular goods or services of a specific industry and thereby subjecting it to digital disruption.

- How can digital disruption be managed at the firmlevel? Since digital disruption often strikes with speed, some organizations may experience it as the rug has suddenly been pulled from under their feet. When effects of digital disruption strike a focal firm more gradually, adaptation may still be severely challenging since it is likely to infer changes that conflict with past strategic choices and investments. For both types of actors, strategies for how to deal with digital disruption are of vital importance.

Once a new logic becomes dominant and core industry conditions are altered, digital disruption is likely to raise both opportunities and challenges for individual firms that seek to enter or remain within an industry. As exemplified by the range of similar services that have emerged in the wake of Uber (Elbanna and Newman 2016), digital innovations that cause digital disruption may act as both battering rams and role models for imitators. As with Spotify, which provided easy and free access to massive music libraries with the help of peer-to-peer technology in a legal manner (Skog et al. 2018), it may also be possible for actors to repurpose deviant logics and their technological materialization to launch new digital disruption processes. In contrast, for actors that have strategically invested and planned according to conditions that are dissolving, digital disruption will likely pose significant challenges. Often, such actors will have to choose between decline and fundamental organizational change that may entail managing dilemmas such as cannibalization of a previously successful business.

Acknowledgements Financial support is gratefully acknowledged from Marianne and Marcus Wallenberg's foundation.

Open Access This article is distributed under the terms of the Creative Commons Attribution 4.0 International License (http://crea tivecommons.org/licenses/by/4.0/), which permits unrestricted use, distribution, and reproduction in any medium, provided you give appropriate credit to the original author(s) and the source, provide a link to the Creative Commons license, and indicate if changes were made.

\section{References}

Adomavicius G, Bockstedt JC, Gupta A, Kauffman RJ (2008) Making sense of technology trends in the information technology landscape: a design science approach. MIS Q 32(4):779-809

Berghaus S, Back A (2016) Stages in digital business transformation: results of an empirical maturity study. In: Mediterranean conference on information systems, p 22 
Bonnet D, Buvat J, Subrahmanyam K (2015) When digital disruption strikes: how can incumbents respond? Cap Gemini Consulting. https://www.capgemini.com/consulting/resources/when-digitaldisruption-strikes. Accessed 26 June 2018

Chase R (2016) We need to expand the definition of disruptive innovation. In: Harv Bus Rev. https://hbr.org/2016/01/we-needto-expand-the-definition-of-disruptive-innovation. Accessed 26 June 2018

Christensen CM (1997) The innovators dilemma: when new technologies cause great firms to fail. Harvard Business School Press, Boston

Christensen CM (2006) The ongoing process of building a theory of disruption. J Prod Innov Manag 23(1):39-55

Christensen CM, Raynor M, McDonald R (2015) What Is disruptive innovation? In: Harvard business review. https://hbr.org/2015/ 12/what-is-disruptive-innovation. Accessed 26 June 2018

de Reuver M, Sørensen C, Basole RC (2017) The digital platform: a research agenda. J Inf Technol 33(2):124-135

El Sawy OA, Malhotra A, Park Y, Pavlou PA (2010) Research commentary-seeking the configurations of digital ecodynamics: it takes three to tango. Inf Syst Res 21(4):835-848

Elbanna A, Newman M (2016) Disrupt the disruptor: rethinking "disruption" in digital innovation. In: Mediterranean Conference on Information Systems, p 58

Farrall F, Harding C, Hillard R et al (2012) Digital disruption: short fuse, big bang? In: Building the lucky country-business imperatives for a prosperous Australia. Deloitte. https://www2. deloitte.com/au/en/pages/building-lucky-country/articles/digitaldisruption-harnessing-the-bang.html. Accessed 26 June 2018

Fichman RG, Dos Santos BL, Zheng ZE (2014) Digital innovation as a fundamental and powerful concept in the information systems curriculum. MIS Q 38(2):329-343

Garcia C, Alvarez Tabio F, Bonnet D, Buvat J (2015) Strategies for the age of digital disruption. In: Digital transformation review. Cap Gemini Consulting. https://www.capgemini.com/consulting/ resources/digital-transformation-review-7-strategies-for-the-ageof-digital-disruption. Accessed 26 June 2018

Garud R, Jain S, Kumaraswamy A (2002) Institutional entrepreneurship in the sponsorship of common technological standards: the case of Sun Microsystems and Java. Acad Manag J 45(1):196-214

Gawer A, Phillips N (2013) Institutional work as logics shift: the case of Intel's transformation to platform leader. Organ Stud 34(8):1035-1071

Hinings B, Gegenhuber T, Greenwood R (2018) Digital innovation and transformation: an institutional perspective. Inf Organ 28(1):52-61

Kallinikos J, Aaltonen A, Marton A (2013) The ambivalent ontology of digital artifacts. MIS Q 37(2):357-370

Karimi J, Walter Z (2015) The role of dynamic capabilities in responding to digital disruption: a factor-based study of the newspaper industry. J Manag Inf Syst 32(1):39-81. https://doi. org/10.1080/07421222.2015.1029380

Knickrehm M, Berthon B, Daugherty P (2016) Digital disruption: the growth multiplier. Accenture Strategy

Legner C, Eymann T, Hess T et al (2017) Digitalization: opportunity and challenge for the business and information systems engineering community. Bus Inf Syst Eng 59(4):301-308
Lucas HC, Goh JM (2009) Disruptive technology: how Kodak missed the digital photography revolution. J Strateg Inf Syst 18(1):46-55

Lucas HC Jr, Agarwal R, Clemons EK et al (2013) Impactful research on transformational information technology: an opportunity to inform new audiences. MIS Q 37(2):371-382

Lyytinen K, Rose GM (2003) The disruptive nature of information technology innovations: the case of internet computing in systems development organizations. MIS Q 27(4):557-596

Nambisan S (2018) Architecture vs. ecosystem perspectives: reflections on digital innovation. Inf Organ 28(2):104-106

Nambisan S, Lyytinen K, Majchrzak A, Song M (2017) Digital innovation management: reinventing innovation management research in a digital world. MIS Q 41(1):223-238

Rauch M, Wenzel M, Wagner H-T (2016) The digital disruption of strategic paths: an experimental study. In: International conference on information systems, Dublin

Rolland KH, Mathiassen L, Rai A (2018) Managing digital platforms in user organizations: the interactions between digital options and digital debt. Inf Syst Res 29(2):419-443

Sandberg J, Mathiassen L, Napier N (2014) Digital options theory for IT capability investment. J AIS 15(7):422-453

Selander L, Henfridsson O, Svahn F (2013) Capability search and redeem across digital ecosystems. J Inf Technol 28(3):183-197

Skog DA (2016) Local game, global rules: exploring technological heterogeneity exploitation in digital creative cluster evolution. Indust Innov 23(6):531-550

Skog D, Wimelius H, Sandberg J (2018) Digital service platform evolution: how Spotify leveraged boundary resources to become a global leader in music streaming. In: 51st Hawaii international conference on system sciences. IEEE, Waikoloa

Tan TCF, Tan B, Choi BC et al (2015) Collaborative consumption on mobile applications: a study of multi-sided digital platform GoCatch. In: International conference on mobile business. Fort Worth

Tilson D, Lyytinen K, Sorensen C (2010) Research commentaryDigital infrastructures: the missing IS research agenda. Inf Syst Res 21:748-759

Utesheva A, Simpson JR, Cecez-Kecmanovic D (2015) Identity metamorphoses in digital disruption: a relational theory of identity. Eur J Inf Syst 25(4):344-363

Van Alstyne M, Parker GG, Choudary SP (2016) Pipelines, platforms, and the new rules of strategy. Harv Bus Rev 94(4):54-62

Weill P, Woerner SL (2015) Thriving in an increasingly digital ecosystem. MIT Sloan Manag Rev 56(4):27-34

Wenzel M, Wagner D, Wagner H-T, Koch J (2015) Digitization and path disruption: an examination in the funeral industry. In: European conference on information systems. Münster

Westerman G, Bonnet D (2015) Revamping your business through digital transformation. MIT Sloan Manag Rev 56(3):10-13

Yoo Y, Henfridsson O, Lyytinen K (2010) Research commentarythe new organizing logic of digital innovation: an agenda for information systems research. Inf Syst Res 21(4):724-735

Yoo Y, Boland RJ, Lyytinen K, Majchrzak A (2012) Organizing for innovation in the digitized world. Organ Sci 23(5):1398-1408 